\title{
Clarifying the boundary conditions of value creation within dynamic capabilities framework: a grafting approach
}

\author{
Björn Michaelis ${ }^{1} \cdot$ Shalini Rogbeer ${ }^{2} \cdot$ Lars Schweizer $^{3} \cdot$ Zafer Özleblebici $^{1}$ (D
}

Received: 3 July 2019 / Accepted: 17 June 2020 / Published online: 27 June 2020

(c) The Author(s) 2020

\begin{abstract}
This study extends dynamic capabilities research by examining the underlying and fundamental concepts of capabilities, resource allocation, fungibility, and environmental change with respect to value creation and appropriation (VCA). Scholars generally assume that VCA depends on the amount of resources allocated to generate future capabilities. We diverge from this ability-performance tautology and instead ground dynamic capabilities in a resource allocation framework. By introducing two boundary conditions, we suggest that environmental change and fungibility between current and dynamic capabilities determine whether resource allocation leads to VCA. We believe that our findings not only represent a fruitful path for future research by strategy and organization scholars, but also provide an important contribution to our knowledge of managing resources in dynamic environments to create future capabilities.
\end{abstract}

Keywords Dynamic capabilities $\cdot$ Environmental change $\cdot$ Fungibility $\cdot$ Resource allocation · Value creation

JEL Classification M19 - M29

Zafer Özleblebici

zafer.ozleblebici@gmail.com

Björn Michaelis

Bjoern.Michaelis@the-klu.org

Shalini Rogbeer

shalini.rogbeer@ebs.edu

Lars Schweizer

1.schweizer@em.uni-frankfurt.de

1 Kühne Logistics University, Großer Grasbrook 17, 20457 Hamburg, Germany

2 EBS Business School, Rheingaustraße 1, 65375 Oestrich-Winkel, Germany

3 Goethe University Frankfurt am Main, Theodor-W.-Adorno Platz 4, Grüneburgplatz 1, 60323 Frankfurt am Main, Germany 


\section{Introduction}

Creating and sustaining a competitive advantage is a fundamental issue both in business world and in the field of strategic management (Rumelt et al. 1991). However, in rapidly changing (dynamic) environments, competitive advantage is ephemeral rather than sustainable (D'Aveni 1994; Ilinitch et al. 1996). Today's business world is characterized by rapid change and in such an environment; firms can no longer rely on their resources to retain their extant competitive position. Instead, they must be able to combine the resources in new ways, gain additional resources and dispose of unessential resources, and to do this continually and rapidly if they want to compete successfully. The term 'dynamic capabilities' has emerged in the strategic management literature to define these skills. Dynamic capabilities perspective refers to the ability of the firm to reconfigure its resources by anticipating, reacting to, and leading the environmental change to address rapidly changing environments (Teece et al. 1997) and generate new value-creating strategies (Eisenhardt and Martin 2000). However, even though its reputation in the literature, the dynamic capabilities perspective has been also criticized for its 'ill-defined boundary conditions' and its unclear discussion of 'the effect of dynamic capabilities' (Schilke 2014). For instance, although the primary aim of business is creating and maintaining value (Conner 1991), dynamic capabilities perspective is unclear on a number of issues such as how value is created and appropriated (Zahra et al. 2006; Barreto 2010). Most importantly, environmental change tends to play-at best - a modest role in existing research on dynamic capabilities. In this study, we argue that value creation within dynamic capabilities perspective cannot be understood without understanding the complex effects of environmental change.

Dynamic capabilities have been linked to the formation of sustainable competitive advantage (Teece et al. 1997; Eisenhardt and Martin 2000). Prior studies suggest that the sustainability of competitive advantage depends on the success in resource allocation, that is, success in balancing different functions' roles and in benefitting from the dynamic capabilities within (e.g., Teece 2019; Leiblein et al. 2017; Lin and Tsai 2016; Sune and Gibb 2013; Sirmon et al. 2007). Using the dynamic capabilities perspective to determine how value is created and appropriated, we draw on Bettis et al. (2014:1411) who argued: "Theory is about logical, causal relationships, among a set of concepts". Consequently, we examine the underlying and fundamental concepts of capabilities, resource allocation, fungibility, and environmental change with respect to VCA.

In order to facilitate theory development and intellectual discourse (Teece et al. 1997), we require some acceptable definitions within capabilities framework. A capability is "the capacity to utilize resources to perform a task or an activity, against the opposition of circumstance" (Teece 2014:14). Capabilities are configurations of routines and resources that allow an organization to accomplish its goals (Nelson and Winter 1982), and can usefully be thought of as falling into one of two interconnected (but analytically separable) categories: ordinary capabilities and dynamic capabilities (Teece 2019). Ordinary capabilities, 
"through which a firm makes its living in the short term" (Drnevich and Kriauciunas 2011:255) refer to the current ongoing activities of an organization, such as "operations, administration, and governance of the firm's activities allow the firm to produce and sell a defined (and static) set of products and services" (Teece 2019:8). On the other hand, dynamic capabilities, by contrast, pertain to "the capacity of an organization to purposefully create, extend, or modify its resource base" (Helfat et al. 2007:4) by "extending, modifying, changing, and/or creating ordinary capabilities" (Drnevich and Kriauciunas 2011:255). Therefore, "ordinary capabilities are to a large extent operational, whereas dynamic capabilities are generally strategic in nature" (Teece 2019:7).

However, the relationship between ordinary and dynamic capabilities cannot be easily disentangled without considering environmental change (Teece 2019; Schilke 2014; Helfat and Winter 2011; Arend and Bromiley 2009; Lavie 2006). If the world were static, it would make strategic sense for firms to focus only on their current ongoing activities and ordinary capabilities accordingly; that is, to continue to invest in what they know in such a certain and weak competitive environment (which is still prevalent in less-developed countries). In reality, however, the world is changing so rapidly that today's ordinary capabilities are obsolete tomorrow, such as, Nokia's technological capabilities in making handheld mobile devices. Firms (such as the ones facing weak competition in less-developed countries) operating in a more stable environment with low degree of uncertainty can remain relatively static, but in rapidly changing dynamic environments with high degree of uncertainty or "deep uncertainty" (Teece 2019), firms (such as the ones facing strong competition in advanced economies) must invest more in dynamic capabilities such as R\&D, innovation, product development, strategic decisionmaking, mergers \& acquisitions, and alliance capabilities in order to make known the unknown unknowns. The basic notion of the dynamic capabilities theory claims that the core competencies of an organization should be used to adapt short-term competitive positions that can be used to form longer-term competitive advantage (Teece 2019). To that end, dynamic capabilities facilitate a firm to beneficially build and renew its resources, to reconfigure them as needed to innovate and respond to (or lead to) changes in the business environment (Teece 2019; Pisano 2017; Pisano and Teece 2007; Teece et al. 1997).

The problem of resource allocation is not only a central theme to economics, but also is fundamental to the strategic management of companies (Bower 2017; Maritan and Lee 2017). For instance, Chandler (1962:13) defines business strategy not only as the determination of goals and objectives but also as the "allocation of resources necessary for carrying out these goals". From dynamic capabilities perspective, it is also essential to allocate firm resources to generate dynamic capabilities and then leverage them in an appropriate manner, in order to achieve the longterm competitive advantage (Hill et al. 2016). That brings us to a dilemma: When firms invest in dynamic capabilities, they have de facto fewer resources to allocate to ordinary capabilities. However, the synergy among organizational capabilities is considered as a critical driver for organizational performance (Hill et al. 2016), therefore, ordinary and dynamic capabilities may interact synergistically to give advantages for coping with change (Helfat and Winter 2011). 
The concept of fungibility, "the attributes of the resources, which allow or inhibit their deployment for alternative uses" (Sapienza et al. 2006:924), in our context the ability of firms to alter their current ordinary capabilities so that they become new capabilities is also useful for explaining value creation. For instance, firms can use fungible problem-solving teams to acquire new knowledge about markets or technologies (Eisenhardt and Martin 2000; Vassolo et al. 2004); that is, they use their current capabilities to search for and create new product/market configurations for the future (Barreto 2010). Fungible resource allocation processes give rise to new routines and capabilities that firms may then deploy in the new environment. By the help of fungibility, firms can engage in routinized, path dependent, current ongoing activities while simultaneously exploring new opportunities. Thus, the fungibility concept captures the direct relationship between investments in ordinary and dynamic capabilities.

Given the increasing number of research exploring firms' digital transformation-i.e., the integration of digital technologies into business models and processes-through the dynamic capabilities framework (e.g. Doherty and Conway 2016; Freitag and Brettel 2017, Warner and Wäger 2019, Muhic and Bengtsson 2019) and its influence on business models (e.g. Laudien and Daxböck 2016; Clauss et al. 2019; Del Bosco et al. 2019; Laudien and Pesch 2019; Kraus et al. 2019), it is worth taking the digital transformation domain as an explanatory field to make all these concepts more concrete, and explain them in a more precise manner. Today's digital technologies affect the organisation outside and in, enabling the creation of new business models and transforming the customer experience (Zaki 2019). The firms are also extremely aware that they need to transform strategically by leveraging digital technologies and business models to build value chains and drive differential value creation aimed at enhanced productivity, performance, and profitability (Orji 2019). However, the digital transformation domain differs from traditional forms of strategic changes as digital technologies have increased the speed of change processes-resulting in a rapidly changing environment, yet much more volatile, uncertain, complex and ambiguous (Schoemaker et al. 2018; Loonam et al. 2018). In such an environment, firms can no longer rely on the capabilities that they have gathered to endure their extant competitive position. Instead, they must be able to combine the capabilities in new ways, gain additional capabilities and dispose of surplus capabilities, and to do this repeatedly and rapidly if they are to compete efficaciously (Daniel and Wilson 2003) as described within dynamic capabilities framework. On the other hand, a major challenge firms face during the digital transformation is the competing concern of needing to balance the exploitation of existing capabilities while also building new digital capabilities that are compatible with the path dependencies of the past, namely existing versus requisite capability concern (Svahn et al. 2017). Therefore, firms must manage this concern cohesively by understanding the ins and outs of resource allocation processes with respect to developing capabilities for coping with environmental changes.

In this study, we aim to highlight a perspective that has been underexplored in resource allocation and value creation research within dynamic capabilities framework. We take two approaches to advance the understanding and analysis about VCA within the dynamic capabilities framework. First, we diverge from the potential 
ability-performance tautology. Instead, we firmly ground the dynamic capabilities framework in a resource allocation context. By that, we consider that investments in dynamic capabilities incur important costs that must be acknowledged. Second, we articulate two boundary conditions for VCA: environmental change and fungibilities within the dynamic capabilities perspective. More specifically, our research question can be summarized as follows: What are the main boundary conditions determining value creation within the dynamic capabilities perspective? We believe that by clearly delineating the conditions, under which dynamic capabilities create VCA, we validate dynamic capabilities to be an important strategy theory in explaining how long-term competitive advantage can be created.

\section{Ordinary and dynamic capabilities: review and basic premises}

Firms have basic routines that allow them to perform tasks systematically and reliably (Nelson and Winter 1982; Zollo and Winter 2002; Zott 2003; Teece 2019). These basic daily-established routines are called as ordinary capabilities, which can be categorized in some combination of (1) skilled personnel, including, under certain circumstances, independent contractors; (2) facilities and equipment; (3) processes and routines, including any supporting technical manuals; and (4) the administrative coordination needed to get the job done (Teece 2019:8). For instance, firms use customer order forms to match market requirements and create timely and competitive value. Over time, however, competitive environments change, and ordinary capabilities become mostly insufficient to ensure a firm success and survival, but in weak competitive environments. For example, competition may change rules in an industry, or new technology and technology convergence may completely transform industry barriers. Thus, the dominant logic underlying value creation and appropriation within that industry might change completely, so that ordinary capabilities become obsolete (Leonard-Barton 1992; Winter 2003; Teece 2019). Hence, firms must change their ordinary capabilities to match the new environment, but their ability to reconfigure ordinary capabilities depends on their dynamic capabilities. Although ordinary capabilities allow short-term performance, dynamic capabilities ensure long-term survival in competitive environments. Firms that have dynamic capabilities can generate future ordinary capabilities that fit the environmental requirements. In fact, this "ongoing evolutionary fitness" (Teece 2019:9) is the goal of dynamic capabilities. John Chambers, former CEO of Cisco Systems, also comprehends this reality and recommends that companies must be willing and ready to "change from doing 'the right thing too long' to 'the next big thing", (Chambers 2017 as cited in Teece 2019).

Based on the general overview above, we propose four basic capabilities rooted premises to extend and specify the scope of discussion:

1. Firms regularly develop path-dependent future scenarios that build on present capabilities. They may use mechanisms such as alliances and acquisitions to overcome excessive path dependency and to open promising avenues (Rosenkopf and Nerkar 2001; Lavie 2006; Teece et al. 1997). 
2. Ordinary capabilities vary over time largely because of underlying environments.

3. Dynamic capabilities have to be built through a process of investment in discovery, knowledge generation, and learning (Teece 2019).

4. Capabilities may be (a) current ordinary, (b) future ordinary, or (c) dynamic capabilities. Current and future ordinary capabilities support technical efficiency and productivity, and therefore allow present or future short-term task performance, regardless of how well- or ill-suited the outputs are to the firm's competitive needs (Teece 2007, 2019). Dynamic capabilities, occupying a higher hierarchical level, allow a predictive assessment of the business environment and potential opportunities (Teece 2019), and continually (re)generation of future capabilities, accordingly (Zollo and Winter 2002). For simplicity, we conceptualize current ordinary capabilities (hereafter, current capabilities) as current routines. Dynamic capabilities, in contrast, are the mechanisms that allow future ordinary capabilities (hereafter, future capabilities) to be generated.

We now turn to our specific research foci for better understanding value creation under dynamic capabilities.

\section{Dynamic capabilities and VCA}

Capability theory recognizes that firms usually have capability gaps (between what they have and what they need) that need to be fulfilled in order to build long-term competitive advantage (Teece 2019). Investments in future capabilities lead to dynamic capabilities (Zollo and Winter 2002; Zahra and George 2002; Teece et al. 1997; Rothaermel and Hess 2007). These types of capabilities may operate quite differently on the resource base of the firm and thus may hold differing implications for competitive advantage and accordingly firm performance (Drnevich and Kriauciunas 2011). Scholars have studied on the contributions of dynamic capabilities to firm's performance in order to better explain the link between them. We also draw on the literature to identify three seemingly contradictory theoretical perspectives that might explain how dynamic capabilities are linked with value creation.

\subsection{Perspective 1: The positive relationship}

One view of the dynamic capabilities perspective builds on recognizing that dynamic capabilities are at a higher hierarchical level than ordinary capabilities. Path dependence and absorptive capacity play important roles in whether ordinary activities will significantly affect firms' ability to generate new capabilities (Zahra and George 2002; Teece et al. 1997; Winter 2003; Zollo and Winter 2002). Consequently, firms that have particular capabilities such as technology or market strengths are likely to search for new opportunities within or close to their knowledge base (Grant 1996). These capabilities allow them to spend fewer resources or create more outputs than their rivals (Jacobides et al. 2012), and enable firms' capabilities to bring into line with markets more properly (Drnevich and Kriauciunas 2011; Li and Liu 2014). 
Moreover, when firms already have similar or related knowledge bases, they can better absorb and deploy similar routines to use and leverage the new knowledge bases (Cohen and Levinthal 1990). Experience in conducting change (called double loop learning; Argyris and Schön 1978, 1996) is also important irrespective of whether the future builds on the past. "Transformational experience can influence dynamic capabilities either by reducing the build up of organizational inertia or by creating routines that support organizational change" (King and Tucci 2002: 173). A number of empirical study in the literature also reveal the positive effect of dynamic capabilities on firm performance, and they propose that the greater the environmental dynamism, the stronger the positive relationship ( $\mathrm{Li}$ and Liu 2014; Drnevich and Kriauciunas 2011; Winter 2003; Zollo and Winter 2002). In that scenario, firms improve their subsequent performance by investing in their dynamic capabilities. We therefore suggest:

Proposition 1a The amount of resources allocated to generate future capabilities is positively related with long-term performance.

\subsection{Perspective 2: The negative relationship}

A second perspective argues that dynamic capabilities are not linked with value creation (Lavie 2006; Helfat et al. 2007; Posen and Daniel 2012). This perspective holds that environmental changes might occur unexpectedly, leaving firms unprepared and unable to tap complementary assets from allies to make timely adaptations to new environmental conditions. Moreover, the environment might be so dynamic that it is better to adhere to current capabilities than to plan for possible future options (Posen and Daniel 2012) and while the dynamic capabilities may change the resource base, this renewal may not be necessarily valuable or it may be even irrelevant to the market (Helfat et al. 2007). Implicit in this scenario is that uncertainty requires a number of options and scenarios. Highly dispersed possible options means that firms do not know which future capabilities to invest in, and may invest in multiple, mutually exclusive scenarios, which then requires them to invest considerable resources in dynamic capabilities. At this point, heavy investments may be ineffective, and the effect of dynamic capabilities on long term performance may be negative accordingly. Because uncertainty does not always bring negative outcomes, just on the contrary a large, unexpected event might even result in positive consequences, for instance a customer-generated YouTube video might be very popular and create enormous demand for the product, such as a toy (Teece 2019). Thus, reaction could be better than proaction because uncertainty creates too many options and prohibits full-fledged analyses, ex-ante, of possible outcomes. In this case, current and dynamic capabilities have no direct relationship and only create costs. Therefore, we propose:

Proposition 1b The amount of resources allocated to generate future capabilities is negatively related with long-term performance. 


\subsection{Perspective 3: The curvilinear relationship}

The third perspective is heavily inspired by the exploitation framework (March 1991) arguing that dynamic capabilities explain and capture value creation. If ordinary capabilities are exploited, they yield more experience, such as best practices, and subsequent better short-term performance (March 1991; King and Tucci 2002; Teece 2019). In the long-term, however, environmental changes may cause current capabilities to become irrelevant, since "the presence of well-developed ordinary capabilities (best-practices) in a firm says nothing about whether its current production mix is the right path for the present or the future" (Teece 2017:12). Thus, proactive firms invest ex-ante in dynamic capabilities to generate future capabilities that might meet particular environmental conditions. In that case, they sacrifice short-term performance gains by investing in current capabilities for long-term gains. Given that, firms have limited resources, they can either allocate them to the short-term to support current capabilities or they can divert them to future capabilities. In this situation, current and future capabilities will have a trade-off relationship over time. If firms cannot change their current capabilities, they must invest fewer resources in current ordinary capabilities. Often, they must overcome inertial forces: exploring new knowledge paths requires heavy investments in softer cognitive factors such as mindset changes (King and Tucci 2002; Zollo and Winter 2002; Rosenkopf and Nerkar 2001). On the other hand, if firms neglect to invest in their future, they might compromise their long-term performance. We therefore expect resource allocation to have an inverted U-shaped relationship with dynamic capabilities and long-term performance. Thus, we propose:

Proposition 1c The amount of resources allocated to generate future capabilities has a curvilinear relationship with long-term performance.

\section{Solving inconsistencies: a grafting approach}

So far, we have disentangled three theoretical perspectives regarding links of dynamic capabilities with VCA, conceptualized in $\mathrm{P} 1 \mathrm{a}, \mathrm{P} 1 \mathrm{~b}$, and $\mathrm{P} 1 \mathrm{c}$ respectively (Fig. 1).

P1a builds on the premise that dynamic environments require firms to invest more resources for generating future capabilities that will be more appropriate for future environmental conditions. P1b argues that resources invested for the future capabilities fail to positively affect performance because they may be irrelevant or future environmental conditions. P1c explains that the amount of resources allocated has a curvilinear relationship with performance. This argument builds on the idea of trade-offs between resources allocated to today and resources allocated 

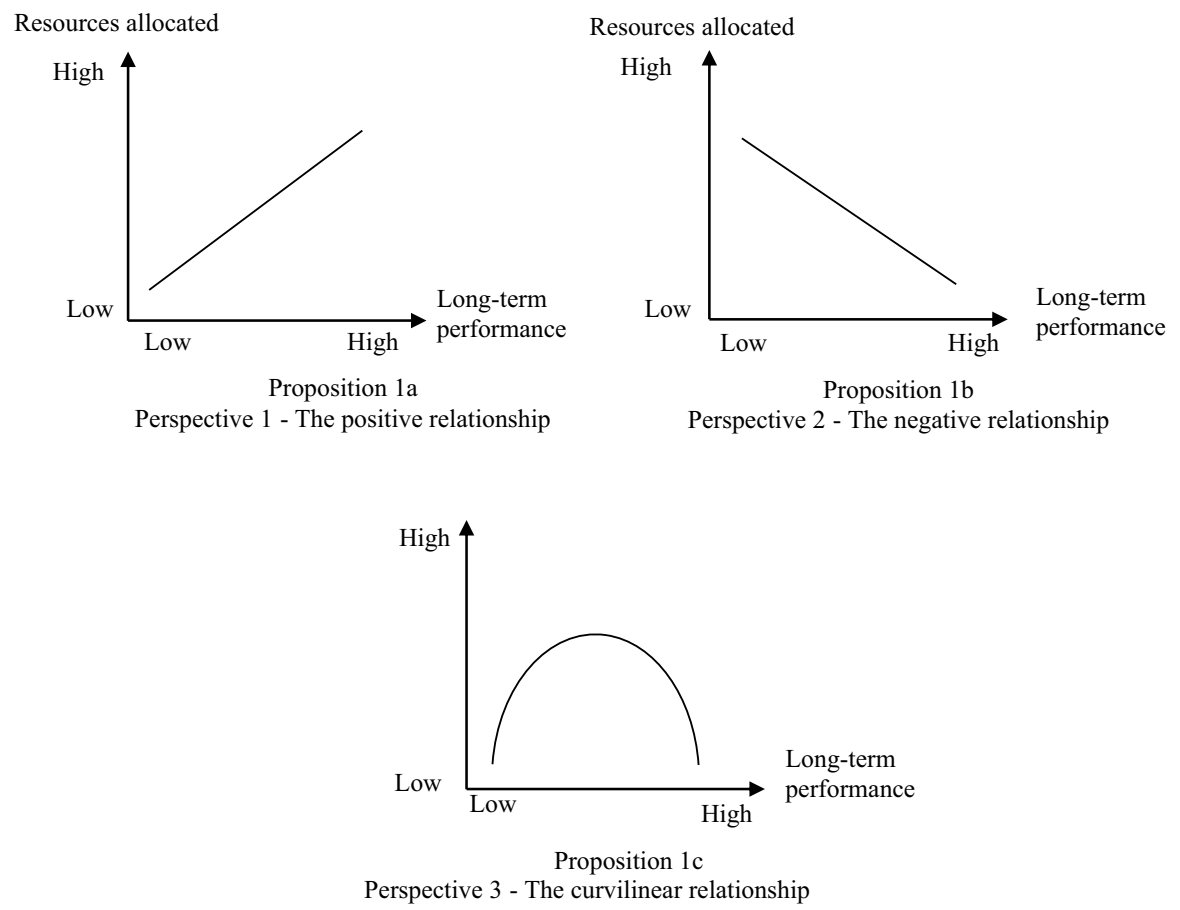

Fig. 1 Resource allocation for future capabilities and the long-term performance

to the future. In short, we need to determine whether it is better to invest in future trade-offs or to build on ordinary capabilities.

P1a explains that investments lead only to positive payoffs (Lavie 2006). Consequently, current and dynamic capabilities have a synergistic relationship: future capabilities will depend on the path dependency configurations of current capabilities. Investments are less costly under conditions of fungibility: future capabilities build on current capabilities, similar to the concept of absorptive capacity (Vassolo et al. 2004; Zahra and George 2002; Cohen and Levinthal 1990).

P1c assumes that investments and costs reach a trade-off. However, investment costs include opportunities to invest in certain future capabilities but not others. P1b and P1c assume that fungibility does not always save costs. Future capabilities developed solely on the notion of fungibility may be inappropriate if the future environment fails to support them. We argue, that environmental change determines whether fungibility works, i.e., when changes are unpredictable or when they are path breaking, fungibility is less likely to work. Furthermore, the investments in capabilities represent firms' endogenous understandings of future needs.

In sum, the propositions build on a number of assumptions and they have inconsistencies. To resolve the inconsistencies or paradoxes raised from these propositions, we draw on Poole and van de Ven (1989), who explained that when theoretical paradoxes are internally inconsistent, they can be solved by introducing new terms. 
Contingency theory suggests that firm performance depends on the alignment of the organization with the environment (external fit), and the compatibility of organizational features with one another (internal fit) (McKee et al. 1989). Correspondingly, we also argue that both fungibility and dimensions of environmental change together play a much more important role in the dynamic capabilities framework than recognized so far.

Penrose (1959) acknowledges how the fungible nature of a firm's resources could create the basis for a firm's growth. Augier and Teece (2007) embrace her ideas and claim that "Penrosean capability perspective" is consistent with elements of the dynamic capabilities framework, and emphasize her ideas of resource fungibility by assessing how the nature of a resource, in particular its fungibility (or lack of it), affected firm's performance. They also criticize that Penrose's emphasis on fungible resources had not received much attention either in the economics or in the strategic management literature (Augier and Teece 2007). Therefore, we believe that adopting a "Penrosean capability perspective" by highlighting the role of fungibility in a capability framework would be also appropriate to solve the inconsistencies between three different perspectives.

The dynamic capabilities perspective embraces environmental change and moves the emphasis from protecting current rare and valuable resources or capabilities from imitation, to attaining recombinations that are rare and valuable in the future. At any point in time, a firm holds a stock of capabilities ranging in a spectrum from highly general purpose (e.g., mechanical engineering, organic chemistry, assembly manufacturing, quality management, financial management, etc.) to highly market-specific (e.g., compact car design, immunotherapeutic cancer drug discovery, retail banking in a particular region, high-volume semiconductor manufacturing, etc.). The firm's capability development strategy could be choices between deepening their existing capabilities versus broadening their range to include new sets of capabilities. Apparently, firms can and even want do both, but resource constrictions force them to make choices at the margin. This also frames firms' resource allocation strategies as choices among different types of capabilities increasing investments. Therefore, the crucial distinguishing character of capabilities in this resource allocation context is their degree of fungibility (Pisano 2017).

On the other hand, while an ordinary capability aims to utilize resources in order to achieve certain short term results (e.g. produce better goods and profits) (Hill et al. 2014), dynamic capabilities are used to integrate and reconfigure a firm's existing resources to respond the challenges within a changing environment (Teece et al. 1997). The majority of the studies on dynamic capabilities, and the seminal work of Teece et al. (1997) emphasize the importance of the environmental change by stressing that dynamic capabilities were necessary to deal with rapidly changing environments. Researchers, accordingly, have examined the efficiency of dynamic capabilities under different levels of environmental change to find out the relationship between dynamic capabilities and environment (e.g. Schilke 2014; Drnevich and Kriauciunas 2011; Oliver and Holzinger 2008; Zahra et al. 2006; Aragon-Correa and Sharma 2003). Although the definitions for ordinary and dynamic capabilities discussed earlier do not explicitly raise the degree of environmental dynamism, the accepted opinion is that dynamic capabilities are more significant in a dynamic 
environment than in a non-dynamic environment since they contribute to change in the firm (Drnevich and Kriauciunas 2011; Chmielewski-Raimondo and Paladino 2007; Helfat et al. 2007). However, despite the central role of environmental change to dynamic capabilities, we identify surprisingly little about how environmental change influences resources allocation for future capabilities to achieve long-term performance.

Helfat and Peteraf (2003:997) argue that "it is difficult to fully explain how firms use resources and capabilities to create a competitive advantage". Nevertheless, by emphasizing the above-mentioned crucial role of fungibility and dimensions of environmental change within dynamic capabilities perspective and moreover their specific effects on the relationship between resource allocation to future capabilities and long-term performance, we can examine how firms, and the managers within them, may generate long term competitive advantage through resource allocation decisions for the future capabilities.

Consequently, we include two new terms into the allocated resources for future capabilities and long-term performance equation: (1) fungibility and (2) dimensions of environmental change. Furthermore, we employ a "grafting approach" (Leiblein et al. 2017; Harris et al. 2013) and consider how VCA within dynamic capabilities framework can be addressed by these two concepts. In particular, we first graft current capabilities, dynamic capabilities, and VCA with fungibility and then, dynamic capabilities, resource allocation, and performance with environmental change.

\subsection{Grafting current capabilities, dynamic capabilities, and VCA with fungibility}

"Fungibility represents a firm-level capability that enables a firm to benefit from redeployment of existing capabilities to new endeavors, thus reducing the cost of each investment" (Vassolo et al. 2004: 1047). For example, the cost of developing resources and capabilities may be viewed as the purchase price of an option to obtain new capabilities. The purchase price may differ significantly across firms. Firms rich in capabilities with adaptability properties for other purposes have few capacity constraints and may be able to apply them readily across the organization (Vassolo et al. 2004). These types of capabilities are fungible. On the other hand, firms under fewer capacity constraints are more likely to redeploy knowledge-based assets for future projects. We focus on fungibilities between current and dynamic capabilities that might have stronger effects on firm performance. For instance, dayto-day problem solving teams that are redeployed to search for longer-term solutions are an example of using fungibility to synergistically enhance performance (Vassolo et al. 2004; Zahra et al. 2006; Helfat and Winter 2011).

Fungibility between current and dynamic capabilities allows firms to realize cost savings through potential economies of scope. Firms with fungible capabilities have more growth opportunities and, if the firm can leverage its existing capabilities pays a lower price for obtaining different options (Vassolo et al. 2004). Furthermore, deployment of fungible capabilities allows firms to leverage and benefit from their experience in related areas. Leveraging existing capabilities requires that these are fungible and involves putting on them to new uses to reduce the costs and time to 
have new ones. In other words, capabilities and resources differ in their degree of fungibility and can only help new product category entry if they are fungible (Danneels 2010). For instance, Smith Corona, once one of the world's primary typewriters manufacturer, was challenged to exercise dynamic capability in the face of the dissipation of its main product category, before its demise in 2001. Decision makers tried to leverage its brand, distribution, and customer understandings, but these efforts did not add value to the new products, since the Smith Corona brand's itself had limited fungibility (Danneels 2010).

On the other hand, prior research on capabilities (in general) and the environmental change indicate that organizational performance will decline whereas the firm's environment becomes more dynamic. This situation occurs especially if the firm's existing capabilities are not flexible and/or aligned with the changing environment (Schilke 2014; Garg et al. 2003; Simerly and Li 2000), and if firms are not able to use their capabilities to adjust to these types of changing environments (Teece et al. 1997; Eisenhardt and Martin 2000). In other words, employing existing capabilities to respond the environmental change is not enough to achieve either competitive advantage or the long-term performance.

Turning back to digital transformation domain as our explanatory field, the existing capabilities of incumbent firms must also involve fungibility or the ability to constantly adapt, change, and be agile. That means having systems and processes (capabilities) in place that have a high degree of adaptability (fungibility) so that when a promising new technology arises (an environmental change); it can be brought into the existing business processes, but into new employment areas. For example, many organizations rely on legacy applications that they refactor piece by piece into cloud-based micro-services that enable further agility (Gruman 2016). Similarly, during the "E-Business Program" at Intel Corp., the IT department serves as an "enabler" of business and focuses on customer demands. It integrates digital technology with existing business processes and connects this to its external business agents (e.g. customers and suppliers), thus enabling managers at both Intel and its external partners to access necessary information for decision making in time and work together through an e-business system (Phan and Stata 2002 cited in Liu et al. 2011). On the other hand, the "Open Plan" by the Woolwich Bank in the UK integrates its information systems with available resources and transforms them into new capabilities to meet customer demands more rapidly. The Woolwich Bank continuously promoted this system throughout its entire organization to generate stronger sustainable competitive advantage (Shah and Siddiqui 2006 cited in Liu et al. 2011). Apparently, firm's digital transformations strategically fit with its external and internal capabilities can engender the firm's competitive advantage (Liu et al. 2011). From this point of view, fungibility can enable a firm to exploit firm's existing capabilities during digital transformation, consequently leading to a new business model that improves the firm's competitive advantage. Therefore, fungibility of the existing capabilities should be considered by the firms to extend the understanding of digital transformation.

We propose that fungibility is positively related with long-term performance. Conversely, without fungibility, performance suffers through lack of experience. Firms that invest in completely new knowledge bases will find it difficult but not 
impossible to benefit from fungibility. In contrast, fungibility is positively related with performance when firms devote considerable resources to creating future capabilities. They then benefit from economies of scope by using and leveraging fungible capabilities. For instance, Toyota's ordinary capabilities in quality created an opportunity for it to enter the luxury car segment; Google's ordinary capabilities in machine learning suggested options for it to make investments in autonomous driving vehicles (Pisano 2017). Since fungible capabilities are more adaptable across different contexts and markets, they provide a hedge against surplus capability enhancing investments for future capabilities. Chris Urmson, Google's head of autonomous-driving car programs supports this argument implicitly by commenting: "It's one of those things that Google, as a company, has had some experience with [e.g., Google Maps product and Street View]. We go around and we have collected this data so you can have this wonderful experience of visiting places remotely. And it's a very similar capability to the one we use here (Madrigal 2014 cited in Pisano 2017:757)." Thus, and irrespective of the relationships we outlined in our scenarios, we propose:

Proposition 2 Fungibility positively moderates the relationship between resources allocated to the generation of future capabilities and long-term performance.

However, fungibility between ordinary and dynamic capabilities may not always enhance performance. Fungibility might actually restrict firms from using current capabilities. Their future capabilities may be inappropriate for future environmental conditions. There are also several cases, in which firms replicating their capabilities inappropriately by putting on existing routines to circumstances where they may not be suitable, for instance, Nestle's transfer of developed-country marketing methods for infant formula to the Third World (Hartley 1989 cited in Teece et al. 1997). In that case, a vital strategic requirement is for firms to monitor capabilities for their applicability to the changing environmental conditions. Therefore, we must probe the various environmental changes that might affect the relationship described in Proposition 2, which brings us to our second grafting.

\subsection{Grafting dynamic capabilities, resource allocation, and performance with environmental change}

Overall, past research has focused on dimensions of environmental dynamism, and has tended to control for environmental change by simply measuring performance across industries of various levels of dynamism and different levels of DC investments, typically R\&D. In other words, the existing literature has paid little attention to the role of configurations of environmental change. However, environmental change is a major component of the DC perspective (Schilke 2014; Helfat et al. 2007) and, when it changes more rapidly; a higher level of dynamic capabilities is required to meet fluctuating needs. We consider four main factors in modeling environmental change: (1) the frequency, (2) the nature of environmental change, (3) 
whether it is exogenous or endogenous, and (4) its predictability (Zahra et al. 2006; Anderson and Tushman 1990).

First, the DC perspective focuses on the frequency of environmental change or the environmental dynamism. Environmental dynamism is a change in the competitive environment affecting how firms compete and how they respond to customer needs and developments in the industry (Drnevich and Kriauciunas 2011), and it concerns the amount of uncertainty arising from the external environment (Baum and Wally 2003). When environments change frequently, that brings high degree of uncertainty or "deep uncertainty" (Teece 2019), wherein firms must invest higher proportions of their resources to future capabilities. This is because frequent changes in environment such as products, customer preferences and technology promptly destroy the effectiveness and efficiency of existing operating routines (Wilhelm et al. 2015). Empirical research has somewhat supported the suppositions that an innovation strategy can build and upgrade dynamic capabilities in rapidly changing environments (Jiao et al. 2011), and firms perform better if they spend more on their R\&D (Kor and Mahoney 2005). For instance, many technology-driven industries exhibit high innovation rates (an indicator of changes in products), a high percentage of sales generated with innovative products (an indicator of changes in customer preferences) and high $R \& D$ expenditures (an indicator of changes in technology) (Wilhelm et al. 2015).

Second, the nature of environmental change determines whether current capabilities are supported or made obsolete. Thus, technological change literature has distinguished between path dependent and path-breaking change (Bourgeois 1985; Teece 1986; Anderson and Tushman 1990; Brown and Eisenhardt 1997; Karim and Mitchell 2000; Lavie 2006; Pisano 2017). The punctuated equilibrium model of change may give further insights into firms' adaptability to change (e.g., Romanelli and Tushman 1994). In general, firms enhance their current capabilities to generate future capabilities (Cohen and Levinthal 1990; Helfat 1994; Teece et al. 1997). However, if the change is path-breaking, it can be detrimental; path independence may cause current capabilities to become obsolete so that firms must use other complementary assets (Laudien and Daxböck 2016; Chandy and Tellis 2000; Tripsas and Gavetti 2000; Tripsas 1997; Teece 1986; Tushman and Anderson 1986). Bob Lutz of General Motors also puts the effect of path-breaking change on current capabilities rather briefly for the automotive industry: "Where the real work of making a car company successful suddenly turns complex, and where the winners are separated from the losers, is in the long-cycle product development process, where short-term day-to-day metrics and the tabulation of results are meaningless" (Teece 2019:10).

However, the firms might overcome the risk through alliances with partners who have diverse but promising knowledge bases (Rosenkopf and Nerkar 2001; Rothaermel and Hess 2007; Lavie 2006). In this case, even under path-breaking environmental change, some firms may be more prepared than others may.

In contrast, environmental change can be path dependent; that is the firm builds on its current capabilities and gains the tools and processes needed to create competitive advantage. Furthermore, if the firm initiates the change, such as by investing in $\mathrm{R} \& \mathrm{D}$ or implementing an innovation strategy to generate new 
technologies other firms may imitate its success, seriously impeding its ability to profit from the innovation (Teece 1986). Otherwise, if firms fail to expect or prepare for major changes, they will focus exclusively on their current capabilities. When environmental conditions support path dependent change, firms that deploy similar and fungible capabilities to generate new capabilities are more likely to benefit. For the arguments of Perspective 2 (the negative relationship) to hold, the firm must have predicted the change, or the change must be path dependent (Tushman and Anderson 1986).

Third, the source of environmental change can be either external environment (exogenous) or internal motivations (endogenous), which proactively and intentionally shape the firm's environment. Exogenous factors of the environmental change such as market and technology turbulence, customer demand shifts, environmental dynamism, and competitive intensity are primarily driven with an assumption that the interaction between dynamic capabilities and ordinary capabilities and resources are triggered by exogenous shocks. An environmental change triggered by an exogenous shock makes it more difficult, costly, time-consuming, hard to fully predict, and ultimately constrained to creating new capabilities. For any given firm in such an exogenous environmental change, investment in future capabilities to respond the change could be essentially economically infeasible, since they would be too costly to develop (Pisano 2017). Therefore, investments in development of these future capabilities in such an environmental change would not guarantee either the competitive advantage or the long-term performance, so that they represent a strategically infeasible option.

Even though the term environmental change usually refers to exogenous changes, environmental change can also be endogenous (Ambrosini and Bowman 2009; Augier and Teece 2009; Eisenhardt and Martin 2000; Van de Ven and Poole 1995). In that case, managerial ambitions (Winter 2000) and managerial proactive behaviour (Ambrosini and Bowman 2009) may be the endogenous causes of change, especially in firms that want to be industry leaders through first-mover advantages (Augier and Teece 2009; Lieberman and Montgomery 1988) or when top managers can sell stakeholders a central vision for decreasing environmental uncertainty (Posen and Daniel 2012; Kotter 2007). Thus, top management may, or may not, initiate change built exclusively on their own cognitions. Although, such endogenous environmental changes may be path-breaking (Pisano 2017; Karim and Mitchell 2000), firms will do better if their resource allocation is in response to endogenous changes by managers who have vision and commitment to overcome organizational doubts and create the right culture for change (Kotter 2007; Van de Ven and Poole 1995). Furthermore, organizations may successfully create new market conditions by making use of fungibilities between ordinary and dynamic capabilities (Vassolo et al. 2004; Eisenhardt and Martin 2000).

Fourth, we must consider whether changes are predictable (Zahra et al. 2006). When firms expect changes, they generate multiple scenarios, assign the probability they will occur, and allocate resources ex-ante. Theoretically, they may allocate resources such as time, managerial attention (or cognition), and financial resources to a number of scenarios. Do DCs actually prepare firms for environmental change? We argue that the more predictable the change, the less likely firms will spread 
resources too thinly by devoting attention, resources, and time to comprehensive scenarios. Some firms may have experience dealing with unexpected changes and are better able to cope with predicted, analyzed, and even actively probed changes (Brown and Eisenhardt 1997).

In sum, the frequency, nature, exogeneity, and predictability of environmental change are likely to determine whether firms can leverage their resources allocated to future capabilities and, therefore, affects the relationship between resource allocation and performance. Therefore, we propose:

Proposition 3a The more frequent, path-breaking, exogenous, and unpredictable the environmental change is, the more the positive relationship between resource allocation and long-term performance will be weakened.

Finally, even when firms spend considerable resources in creating future capabilities and benefit from fungible capabilities, we suggest that when the environmental changes are path-breaking and highly unpredictable, then strong investments through resource allocation and fungibilities might be ineffective. Unpredictable path-breaking changes limit whether firms can redeploy their current capabilities to match the environment. In effect, firms may wrongly generalize their past learnings to redeploy similar capabilities. They must unlearn their experiences to tackle unexpected changes (Hedberg 1981; Huber 1991). "The truly novel and unexpected is much more likely to emerge when the firm opens itself to learning from unstructured, external stimuli" (Zahra et al. 2006: 15). Firms that once drew on the fungibility between ordinary and dynamic capabilities might find themselves severely constrained compared with firms that rely on trial-anderror learning. Thus, the path-breaking nature and unpredictability of change affect the relationship between fungibility and performance. Specifically, we propose:

Proposition 3b The more path-breaking and unpredictable the change is, the more the moderating effect of fungibility on the relationship between resource allocation and long-term performance will be weakened.

Thus far, we have highlighted the prescriptive nature of environmental change, and proposed that the interactive effect of allocated resources to create future capabilities and fungibility between current and dynamic capabilities on long term performance is dependent on the environmental change. Consequently, above argument is captured by the following proposition.

Proposition 3c Environmental change, fungibility, and resources allocated have a three-way interaction on long-term performance.

The conceptual framework of three-way interaction of environmental change, fungibility and resources allocated with long-term performance is illustrated in Fig. 2. 


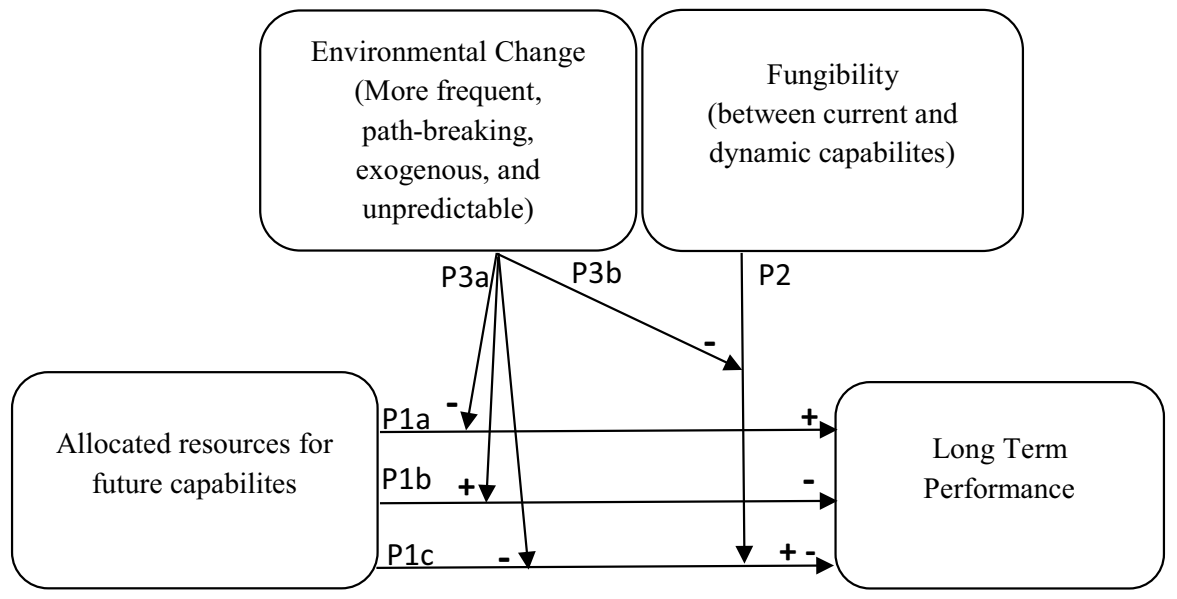

Fig. 2 Conceptual framework of three-way interaction of environmental change, fungibility and resources allocated with long-term performance

\section{Discussion}

To start with, we noted that scholars have attempted to explicate the causal mechanisms underlying DC value creation (Zahra et al. 2006; Helfat et al. 2007). We strengthen DC's theoretical scope by focusing on two fundamental boundary conditions: environmental change and fungibility. Scholars apparently concede that the amount of resources firms invest in the generation of future capabilities will positively affect performance (e.g., Coen and Maritan 2011; Jiang et al. 2010; Kor and Mahoney 2005; Moliterno and Wiersema 2007; Morgan et al. 2009; Slater et al. 2006). We formulated three logical perspectives contradicting the former argumentation. We specifically captured the relationship between investment in future capabilities and performance as the underlying driver of value creation in three perspectives.

Firms can be conceptualized as a configuration of assets and routines-ordinary capabilities - that allow them to perform successfully (Helfat and Winter 2011). However, different than "the old days of stable environments, [where] companies create fairly rigid strategies designed to fit the long-term conditions of the environment" (D'Aveni 1994:215), environmental changes weaken the link between underlying capabilities and the environment, which also reduces the potential for value creation and appropriation (Augier and Teece 2009; Teece et al. 1997).Environmental change affects value creation and consists of four main aspects: (1) whether it occurs more frequently and brings high degree of uncertainty (2) whether it is path breaking or path dependent, (3) whether decision makers endogenously created the change or whether it was exogenously defined, and (4) whether decision makers can predict it.

Furthermore, fungibility is a major source of explaining value creation and appropriation, a concept that sheds light on the relationship between ordinary and dynamic capabilities. Prior studies propose that the sustainability of competitive 
advantage is subject to the success in resource allocation, namely, success in harmonizing different functions' roles and in profiting from the dynamic capabilities within. In this study, we diverge from fungibility's general attribution to resources context, and extend its borders by moving the concept into a capability context in order to explain value creation within DC framework. We argue that fungibility between ordinary and dynamic capabilities positively moderates the relationship between resources allocated to the generation of future capabilities and long-term performance. By adopting a "Penrosean capability perspective" through highlighting the role of fungibility in a capability framework we not only help to solve the inconsistencies between three different perspectives regarding value creation within DC framework, but also broaden the applicability of this concept in strategic management field. We hope that we could also dispel the concerns of Augier and Teece (2007), who criticize the less received attention to the Penrose's emphasis on fungible resources either in the economics or in the strategic management literature.

Moreover, we also argue that the relationship between ordinary and dynamic capabilities is difficult to disentangle without considering environmental change (Teece 2019; Helfat and Winter 2011; Arend and Bromiley 2009; Lavie 2006). In fact, environmental change may exclusively determine whether resources are allocated to ordinary capabilities or to dynamic capabilities.

Our research differs from previous works in attempting to develop the boundary conditions under which DC creates value by exposing the links between two underlying concepts, namely fungibility and environmental change. In particular, previous research (e.g., Teece et al. 1997; Teece 2019) has established that in dynamic environments, firms should invest in future capabilities. However, we take a different stance in proposing that investment is only one part of the story. We extend existing research by grafting fungibility and environmental change with ordinary and dynamic capabilites, resorce allocation, and VCA. After this grafting approach, we argue that fungibility and environmental change must be considered if we strive to disentangle the value creation mechanism.

Supporting our argument, the influences of digital technologies on business have transformed significantly over the decades, and consequently made many business models obsolete (Clauss et al. 2019; Del Bosco et al. 2019; Laudien and Pesch 2019; Kraus et al. 2019). Consequently, digital transformation has become increasingly vital for firms pursuing to survive and enhance competitive advantage in such a rapidly changing environment, in which the transformation process itself becomes complex and chaotic in its nature and might actually produce a drastic departure from the current state. However, in such an endeavor, managing digital transformation by simply investing in future capabilities can be also inefficacious, since digitalization accelerates organizational change and amplifies environmental complexity, volatility, and uncertainty (Warner and Wäger 2019). This means that investment in future capabilities is a necessary but not a sufficient prerequisite for building dynamic capabilities and enhancing competitive advantage. Therefore, the two boundary conditions demonstrating the necessity of the awareness of and readiness for analysis of both the capabilities and external demands through the fungibility and environmental change lenses are even more crucial in digital transformation domain in terms of resource allocation for value creation. 
In addition, our research has also empirical implications. We shed some light on the use and development of potentially theoretically valid constructs. So far, the constructs used to measure dynamic capabilities empirically are used to measure other theoretical constructs as well. For instance, R\&D can be considered as one dynamic capability but dynamic capabilities include absorptive capacity, exploration efforts, or asset-specific transactions. As a result, many researchers doubt the usefulness of such a theory (see Arend and Bromiley 2009, for a review). Our approach to resource allocation brings us closer to the dynamic capabilities perspective. This paper provides a starting point for discussion and is not without limitations. Future research could ask decision makers about their resource allocation processes and about whether environmental change or fungibility is applied in those cases. Only by conceptualizing constructs with higher levels of discriminant validity we can advance the dynamic capabilities agenda. In particular, our research could be enhanced by collecting data from key decision makers regarding resource allocation patterns, fungibilities deployed over time, and the endogenous nature of change.

Moreover, we provide important insights to managers in helping them understand the intricacies of resource allocation processes, which remain the fundamental economic task of a corporate management (Bower 2017) with respect to developing capabilities for coping with environmental changes. Lying at the heart of dynamic capabilities are several fundamental management/organizational skills including investment/resource allocation decision heuristics (Teece 2006). Therefore, we argue that managerial cognition about firm capabilities and the nature of the environmental change is crucial to explaining the exercise of dynamic capabilities, since the identification of capabilities, and the understanding of their fungibility affect which directions of renewal are pursued in a dynamic environment. We believe that managers in dynamic environments, for instance the ones managing the firms' digital transformation, should not simply allocate more resources toward creating future capabilities. Increasing resource allocation might exacerbate problems especially in the absence of fungibilities or when environmental change is path breaking and unpredictable. In fact, managers are advised to opt for more improvisation or trialand-error learning when their forecasted scenarios do not unfold.

\section{Concluding remarks}

The dynamic capabilities perspective still needs to address the fundamental strategy question of value creation and appropriation because it aims to explain how firms perform under conditions of change, and whether proactive firms-those that are prepared for and make necessary investments in anticipation of future change-perform better. However, beyond controlling for environmental change and industry effects, researchers have generally underplayed environmental change as it affects the dynamic capabilities framework's value creation potential.

Our main goal is to determine when firms perform better over the long run by preparing for future environmental change. Furthermore, our conceptualization aims to overcome the ability-performance tautology by examining how resource allocation processes, environmental change, and fungibility affect underlying dynamic 
capabilities and by reflecting on the potential of dynamic capabilities to create value. We developed three scenarios in which investments in future capabilities affect value creation. We show that two boundary conditions must be present. More specifically, we outline the importance of path-breaking, unpredictable, and exogenous environmental change. Our findings also suggest that fungibility is important for creating value under the dynamic capabilities framework. By introducing two boundary conditions, we suggest that environmental change and fungibility between current and dynamic capabilities determine whether resource allocation leads to VCA. More specifically, the two boundary conditions suggest that investments in building dynamic capabilities should be strategically justified by cognition about firm capabilities (understanding of their fungibility), and the nature of the environmental change. Therefore, we argue that fungibility and environmental change must be considered if we strive to disentangle the value creation mechanism.

We believe that our approach and propositions not only represent a fruitful path for future research by strategy and organization scholars, but also provide an important contribution to our knowledge of managing resources in dynamic environments to create future capabilities. We hope that we contribute to the continuing debate on the role and performance consequences of dynamic capabilities.

Acknowledgements Open Access funding provided by Projekt DEAL.

Open Access This article is licensed under a Creative Commons Attribution 4.0 International License, which permits use, sharing, adaptation, distribution and reproduction in any medium or format, as long as you give appropriate credit to the original author(s) and the source, provide a link to the Creative Commons licence, and indicate if changes were made. The images or other third party material in this article are included in the article's Creative Commons licence, unless indicated otherwise in a credit line to the material. If material is not included in the article's Creative Commons licence and your intended use is not permitted by statutory regulation or exceeds the permitted use, you will need to obtain permission directly from the copyright holder. To view a copy of this licence, visit http://creativecommons.org/licen ses/by/4.0/.

\section{References}

Ambrosini V, Bowman C (2009) What are dynamic capabilities and are they a useful construct in strategic management. Int J Manag Rev 11(1):29-49

Anderson P, Tushman ML (1990) Technological discontinuities and dominant designs: a cyclical model of technological change. Adm Sci Q 35:604-633

Aragon-Correa J, Sharma S (2003) A contingent resource-based view of proactive environmental strategy. Acad Manag Rev 28:71. https://doi.org/10.2307/30040690

Arend RJ, Bromiley P (2009) Assessing the dynamic capabilities view: spare change, everyone? Strateg Org 7:75-90

Argyris C, Schön DA (1978) Organizational learning: a theory of action perspective. Addison-Wesley, Reading

Argyris C, Schön DA (1996) Organizational learning II. Theory, method, and practice. Addison-Wesley, Reading

Augier M, Teece DJ (2007) Dynamic capabilities and multinational enterprise: Penrosean insights and omissions. Manage Int Rev 47(2):175-192

Augier M, Teece DJ (2009) Dynamic capabilities and the role of managers in business strategy and economic performance. Organ Sci 20(2):410-421 
Barreto I (2010) Dynamic capabilities: a review of past research and an agenda for the future. J Manag $36: 256-280$

Baum JR, Wally S (2003) Strategic decision speed and firm performance. Strateg Manag J 24:1107-1129

Bettis RA, Gambardella A, Helfat C, Mitchel W (2014) Theory in strategic management. Strateg Manag J 35:1411-1413

Bourgeois LJ (1985) Strategic goals, perceived uncertainty, and economic performance in volatile environments. Acad Manag J 28(3):548-573

Bower JL (2017) Managing resource allocation: personal reflections from a managerial perspective. J Manag 43(8):2421-2429

Brown SL, Eisenhardt KM (1997) The art of continuous change: linking complexity theory and timepaced evolution in relentlessly shifting organizations. Adm Sci Q 42:1-34

Chambers J (2017) Turning setbacks into success. linkedin.com. https://www.linkedin.com/pulse/turningsetbacks-success-john-chambers. Accessed 20 April 2017

Chandler AD (1962) Strategy and structure: chapters in the history of American enterprise. MIT Press, Cambridge

Chandy RK, Tellis GJ (2000) The incumbent's curse? Incumbency, size, and radical product innovation. J Market 64(3):1-17

Chmielewski-Raimondo D, Paladino A (2007) Driving a resource orientation: reviewing the role of resource and capability characteristics. Manag Decis 45:462-483

Clauss T, Harengel P, Hock M (2019) The perception of value of platform-based business models in the sharing economy: determining the drivers of user loyalty. Rev Manag Sci 13:605-634

Coen CA, Maritan CA (2011) Investing in capabilities: the dynamics of resource allocation. Organ Sci 22:99-117

Cohen WM, Levinthal DA (1990) Absorptive capacity: a new perspective on learning and innovation. Adm Sci Q 35:128-152

Conner KR (1991) A historical comparison of resource-based theory and five schools of thought within industrial organization economics: do we have a new theory of the firm? J Manag 17:121-154

D'Aveni RA (1994) Hypercompetition: managing the dynamics of strategic maneuvering. Free Press, New York

Daniel EM, Wilson HN (2003) The role of dynamic capabilities in e-business transformation. Eur J Inf Syst 12:282-296

Danneels E (2010) Trying to become a different type of company: dynamic capability at Smith Corona. Strateg Manag J 32(1):1-31

Del Bosco B, Chierici R, Mazzucchelli A (2019) Fostering entrepreneurship: an innovative business model to link innovation and new venture creation. Rev Manag Sci 13:561-574

Doherty E, Conway G (2016) A dynamic capability approach to digital transformation: a focus on key foundational themes. In Proceedings of the 10th European conference on information systems management, pp 20-28

Drnevich P, Kriauciunas A (2011) Clarifying the conditions and limits of the contributions of ordinary and dynamic capabilities to relative firm performance. Strateg Manag J 32:254-279

Eisenhardt KM, Martin JA (2000) Dynamic capabilities: what are they? Strateg Manag J 21:1105-1121

Freitag PM, Brettel M (2017) Building up dynamic capabilities for the digital age. In: Acad Manage Rev Proceedings

Garg V, Walters B, Priem R (2003) Chief executive scanning emphases, environmental dynamism, and manufacturing firm performance. Strateg Manag J 24:725-744

Grant RM (1996) Toward a knowledge-based theory of the firm. Strateg Manag J 17:109-122

Gruman G (2016) What digital transformation really means. InfoWorld. https://www.infoworld.com/artic le/3080644/what-digital-transformation-really-means.html. Accessed 11 May 2019

Harris JD, Johnson SG, Souder D (2013) Model-theoretic knowledge accumulation: the case of agency theory and incentive alignment. Acad Manag Rev 38:442-454

Hartley RF (1989) Marketing mistakes. Wiley, New York

Hedberg B (1981) How organizations learn and unlearn. In: Nyström PC, Starbuck WH (eds) Handbook of organizational design 1. Oxford University Press, Oxford, pp 3-27

Helfat C (1994) Evolutionary trajectories in petroleum firm R\&D. Manag Sci 40:1720-1747

Helfat CE, Peteraf MA (2003) The dynamic resource based view: capabilities life cycles. Strateg Manag J 24:997-1010

Helfat CE, Winter SG (2011) Untangling dynamic and operational capabilities: strategy for the (n)everchanging world. Strateg Manag J 32:1243-1250 
Helfat CE, Finkelstein S, Mitchell W, Peteraf MA, Singh H, Teece DJ, Winter SG (2007) Dynamic capabilities: understanding strategic change in organizations. Blackwell, London

Hill CWL, Jones GR, Schilling MA (2014) Strategic management: an integrated approach. Cengage Learning, Boston

Hill CWL, Schilling MA, Jones GR (2016) Strategic management: an integrated approach. Cengage Learning

Huber GP (1991) Organizational learning: the contributing processes and the literatures. Organ Sci 2(1):88-115

Ilinitch A, D'aveni R, Lewin A (1996) New organisational forms and strategies for managing in hypercompetitive environments. Organ Sci 7:211-220

Jacobides M, Winter S, Kassberger S (2012) The dynamics of wealth, profit and sustainable advantage. Strateg Manag J 33:1384-1410. https://doi.org/10.1002/smj.1985

Jiang RJ, Tao QT, Santoro MD (2010) Alliance portfolio diversity and firm performance. Strateg Manag J 31:1136-1144

Jiao H, Alon I, Cui Y (2011) Environmental dynamism, innovation, and dynamic capabilities: the case of China. J Enterp Commun People Places Glob Econ 5(2):131-144

Karim S, Mitchell W (2000) Path-dependent and path-breaking change: reconfiguring business resources following acquisitions in the US medical sector, 1978-1995. Strateg Manag J 21:1061-1081

King AA, Tucci CL (2002) Incumbent entry into new market niches: the role of experience and managerial choice in the creation of dynamic capabilities. Manag Sci 48:171-186

Kor YY, Mahoney JT (2005) How dynamics, management, and governance of resource deployments influence firm-level performance. Strateg Manag J 26:489-496

Kotter JP (2007) Leading change. HBR's 10 must Reads on Change, vol 2. Harvard Business Review, Brighton

Kraus S, Roig-Tierno N, Bouncken RB (2019) Digital innovation and venturing: an introduction into the digitalization of entrepreneurship. Rev Manag Sci 13:519-528

Laudien SM, Daxböck B (2016) The influence of the industrial internet of things on business model design: a qualitative-empirical analysis. Int J Innov Manag 20:1640014. https://doi.org/10.1142/ S1363919616400144

Laudien SM, Pesch R (2019) Understanding the influence of digitalization on service firm business model design: a qualitative-empirical analysis. Rev Manag Sci 13:575-587

Lavie D (2006) Capability reconfiguration: an analysis of incumbent responses to technological change. Acad Manag Rev 31(1):153-174

Leiblein MJ, Chen JS, Posen HE (2017) Resource allocation in strategic factor markets: a realistic real options approach to generating competitive advantage. J Manag 43(8):2588-2608

Leonard-Barton D (1992) Core capabilities and core rigidities: a paradox in managing new product development. Strateg Manag J 13:111-125

Li D, Liu J (2014) Dynamic capabilities, environmental dynamism, and competitive advantage: evidence from China. J Bus Res 67(1):2793-2799

Lieberman MB, Montgomery DB (1988) First-mover advantages. Strateg Manag J 9(1):41-58

Lin C, Tsai HL (2016) Achieving a firm's competitive advantage through dynamic capability. Balt J Manag 11(3):260-285

Liu DY, Chen SW, Chou TC (2011) Resource fit in digital transformation : lessons learned from the CBC Bank global e-banking project. Manag Decis 49:1728-1742

Loonam J, Eaves S, Kumar V, Parry G (2018) Towards digital transformation: lessons learned from traditional organizations. Strateg Change 27(2):101-109

Madrigal A (2014) The trick that makes Google's self-driving cars work. The Atlantic, May 15, 2014 http://www.theatlantic.com/technology/archive/2014/05/all-the-world-a-track-the-trick-thatmakes-googles-self-driving-cars-work/370871/. Accessed 16 June 2019

March JG (1991) Exploration and exploitation in organizational learning. Organ Sci 2(1):71-87

Maritan CA, Lee GK (2017) Resource allocation and strategy. J Manag 43(8):2411-2420

McKee DO, Varadarajan PR, Pride WM (1989) Strategic adaptability and firm performance: a market contingent perspective. J Market 53:21-35

Moliterno TF, Wiersema MF (2007) Firm performance, rent appropriation, and the strategic resource divestment capability. Strateg Manag J 28:1065-1087

Morgan NA, Vorhies DW, Mason CH (2009) Market orientation, marketing capabilities, and firm performance. Strateg Manag J 30:909-920 
Muhic M, Bengtsson L (2019) Dynamic capabilities triggered by cloud sourcing: a stage-based model of business model innovation. Rev Manag Sci. https://doi.org/10.1007/s11846-019-00372-1

Nelson RR, Winter SG (1982) An evolutionary theory of economic change. Harvard University Press, Cambridge

Oliver C, Holzinger I (2008) The effectiveness of strategic political management: a dynamic capabilities framework. Acad Manag Rev 33:496-520. https://doi.org/10.5465/AMR.2008.31193538

Orji CI (2019) Digital business transformation: towards an integrated capability framework for digitization and business value generation. J Glob Bus Technol 15(1):47-57

Penrose ET (1959) The theory of the growth of the firm. Oxford University Press, Oxford

Phan DD, Stata NM (2002) E-business success at Intel: an organization ecology and resource dependence perspective. Ind Manag Data Syst 102(4):211-217

Pisano GP (2017) Toward a prescriptive theory of dynamic capabilities: connecting strategic choice, learning, and competition. Ind Corp Change 26(5):747-762

Pisano GP, Teece DJ (2007) How to capture value from innovation: shaping intellectual property and industry architecture. Calif Manag Rev 50(1):278-296

Poole SP, van de Ven AH (1989) Using paradox to build management and organization theories. Acad Manag Rev 14(4):562-578

Posen HE, Daniel DA (2012) Chasing a moving target: exploitation and exploration in dynamic environments. Manag Sci 58(3):587-601

Romanelli E, Tushman ML (1994) Organizational transformation as punctuated equilibrium: An empirical test. Acad Manag J 37(5):1141-1166

Rosenkopf L, Nerkar A (2001) Beyond local search: boundary-spanning, exploration, and impact in the optical disk industry. Strateg Manag J 22(4):287-306

Rothaermel FT, Hess AM (2007) Building dynamic capabilities: innovation driven by individual-, firm-, and network-level effects. Organ Sci 18(6):898-921

Rumelt RP, Schendel D, Teece DJ (1991) Strategic management and economics. Strateg Manag J 12(Winter):5-29

Sapienza H, Autio E, George G, Zahra S (2006) A capabilities perspective on the effects of early internationalization on firm survival and growth. Acad Manag Rev 31(4):914-933

Schilke O (2014) On the contingent value of dynamic capabilities for competitive advantage: the nonlinear moderating effect of environmental dynamism. Strateg Manag J 35(2):179-203

Schoemaker PJH, Heaton S, Teece D (2018) Innovation, dynamic capabilities, and leadership. Calif Manag Rev 61(1):15-42

Shah MH, Siddiqui FA (2006) Organizational critical success factors in adoption of E-banking at the Woolwich bank. Int J Inf Manag 26(6):442-456

Simerly R, Li M (2000) Environmental dynamism, capital structure and performance: a theoretical integration and an empirical test. Strateg Manag J 21:31-49

Sirmon D, Hitt M, Ireland R (2007) Managing firm resources in dynamic environments to create value: looking inside the black box. Acad Manag Rev 32(1):273-292

Slater SF, Olson EM, Hult GTM (2006) The moderating influence of strategic orientation on the strategy formation capability-performance relationship. Strateg Manag J 27:1221-1231

Sune A, Gibb J (2013) Using dynamic capabilities to transform a firm's resource base: bridging path creation and path dependency. In: Druid Conference, Barcelona, Spain

Svahn F, Mathiassen L, Lindgren R (2017) Embracing digital innovation in incumbent firms: how Volvo cars managed competing concerns. MIS Q 41(1):239-253

Teece DJ (1986) Profiting from technological innovation: implications for integration, collaboration, licensing and public policy. Res Policy 15(6):285-305

Teece DJ (2006) Reflections on "Profiting from Innovation". Res Policy 35(8):1131-1146

Teece DJ (2007) Explicating dynamic capabilities: the nature and microfoundations of (sustainable) enterprise performance. Strateg Manag J 28(13):1319-1350

Teece DJ (2014) A dynamic capabilities-based entrepreneurial theory of the multinational enterprise. J Int Bus Stud 45:8-37

Teece DJ (2017) A capability theory of the firm: an economics and (strategic) management perspective. Working Paper Series No. 20, Tusher Center for the Management of Intellectual Capital

Teece DJ (2019) A capability theory of the firm: an economics and (strategic) management perspective. New Zeal Econ Pap 53(1):1-43

Teece DJ, Pisano G, Shuen A (1997) Dynamic capabilities and strategic management. Strateg Manag J 18:509-533 
Tripsas M (1997) Unraveling the process of creative destruction: complementary assets and incumbent survival in the typesetter industry. Strateg Manag J 18(1):119-142

Tripsas M, Gavetti G (2000) Capabilities, cognition, and inertia: evidence from digital imaging. Strateg Manag J 21(10-11):1147-1161

Tushman ML, Anderson P (1986) Technological discontinuities and organizational environments. Admin Sci Q 31:439-465

Van de Ven AH, Poole MS (1995) Explaining development and change in organizations. Acad Manag Rev 20(3):510-540

Vassolo RS, Anand J, Folta TB (2004) Non-additivity in portfolios of exploration activities: a real options based analysis of equity alliances in biotechnology. Strateg Manag J 25(11):1045-1061

Warner KSR, Wäger M (2019) Building dynamic capabilities for digital transformation: an ongoing process of strategic renewal. Long Range Plan 52:326-349

Wilhelm H, Schlömer M, Maurer I (2015) How dynamic capabilities affect the effectiveness and efficiency of operating routines under high and low levels of environmental dynamism. Brit $\mathbf{J}$ Manag 26:327-345

Winter SG (2000) The satisficing principle in capability learning. Strateg Manag J 21:981-996

Winter SG (2003) Understanding dynamic capabilities. Strateg Manag J 24:991-995

Zahra SA, George G (2002) Absorptive capacity: a review, reconceptualization, and extension. Acad Manag Rev 27:185-203

Zahra SA, Sapienza HJ, Davidsson P (2006) Entrepreneurship and dynamic capabilities: a review, model and research agenda. J Manag Stud 43(4):917-955

Zaki M (2019) Digital transformation: harnessing digital technologies for the next generation of services. J Serv Mark 33(4):429-435

Zollo M, Winter SG (2002) Deliberate learning and the evolution of dynamic capabilities. Organ Sci 13:339-351

Zott C (2003) Dynamic capabilities and the emergence of intraindustry differential firm performance: insights from a simulation study. Strateg Manag J 24:97-125

Publisher's Note Springer Nature remains neutral with regard to jurisdictional claims in published maps and institutional affiliations. 